Max-Planck-Institut für demografische Forschung

Max Planck Institute for Demographic Research

Konrad-Zuse-Strasse 1 - D-18057 Rostock - GERMANY

$\mathrm{Tel}+49$ (0) 3812081 - 0; Fax +49 (0) 3812081 - 202;

http://www.demogr.mpg.de

MPIDR WORKING PAPER WP 2009-013

MAY 2009 (REVISED JANUARY 2010)

\title{
Trends in geographical mortality differentials in India
}

\author{
Nandita Saikia (nanditasts@gmail.com) \\ Domantas Jasilionis (jasilionis@demogr.mpg.de) \\ Faujdar Ram (fram@iips.net) \\ Vladimir Shkolnikov (shkolnikov@demogr.mpg.de)
}

(C) Copyright is held by the authors.

Working papers of the Max Planck Institute for Demographic Research receive only limited review. Views or opinions expressed in working papers are attributable to the authors and do not necessarily reflect those of the Institute. 


\title{
Trends in geographical mortality differentials in India
}

\author{
Nandita Saikia (nanditasts@gmail.com) \\ Domantas Jasilionis (jasilionis@demogr.mpg.de) \\ FaujdarRam (fram@iips.net) \\ Vladimir Shkolnikov (shkolnikov@demogr.mpg.de)
}




\title{
Trends in geographical mortality differentials in India*
}

\author{
Nandita Saikia \\ International Institute for Population Sciences \\ Govandi Station Road, Deaonar, Mumbai-400088, India \\ e-mail: nanditasts@gmail.com \\ Domantas Jasilionis \\ Max Planck Institute for Demographic Research, Rostock, Germany \\ e-mail: jasilionis@demogr.mpg.de \\ Faujdar Ram \\ International Institute for Population Sciences, Mumbai, India \\ e-mail: fram@iips.net \\ Vladimir Shkolnikov \\ Max Planck Institute for Demographic Research, Rostock, Germany \\ e-mail: shkolnikov@demogr.mpg.de \\ * Dedicated to the memory of our colleague Prof. Mari Bhat
}

\section{Abstract}

The study examines variation of mortality and mortality trends among different regions in India since the 1970s by using data of the Sample Registration System (SRS). Evaluation of the SRS data quality confirms reliability for children and adult ages under 60. Analysis of temporary life expectancy between the exact ages 0 and 60 years shows that after a spectacular progress during the 1970s and the 1980s, improvements in longevity slowed down in the 1990s and 2000s. Gini coefficient and dispersion measure of mortality confirm the convergence of mortality across the regions in India between 1971-75 and 2000-2004. In spite of this trend, a substantial difference between higher longevity in the south and lower longevity in the north was noteworthy in 20012004. Age-decomposition of temporary life expectancy by age group 0-14 and 15-59 suggests that the steep longevity increase in the 1970s-80s was largely driven by mortality reduction of children under age 15 . In the 1990 s and the early 2000 s, the contribution of both young and adult age groups into the longevity increase has diminished. India faces difficulties in making progress in further reduction of infant death to the minimum levels and also in fight with chronic and man-made diseases at older ages. 


\section{Introduction}

Health inequalities between and within countries is a matter of growing concern internationally (Marmot, 2005). In 2001-05, the life expectancy at birth for a females living in urban Kerala was 76.7 year whereas the corresponding figure for females in rural Madhya Pradesh was only 56.0 years (ORG, 2006). Thus, the maximal regional life expectancy gap in India constituted about 21 years! Life expectancy differentials are even more striking in case of socio-economic status as the mortality burden falls disproportionately on economically disadvantaged and lower-caste groups (Subrmanian et al. 2006; Dyson \& Moore, 1983).

What is known about regional mortality variation in India? First, many authors observe a clear north-south demographic division which is reflected by almost all demographic indicators including infant and child mortality (Dyson \& Moore, 1983; Murthi, Guio, Dreze, 1995). Some recent studies confirm that excess female child mortality in India varies considerably across regions reaching its highest levels in the north (Arokiasamy, 2004; Subramanian et al. 2006). Much less is known about principal regularities of regional differentials in all age mortality and, especially, in adult mortality. In his fundamental study on mortality trends and patterns in India, Bhat (1987) found that although southern states experienced significantly lower levels of child mortality, adult mortality appears to be somewhat lower in the north-western parts of the country. The study confirmed that regional differentiation in adult mortality is significantly smaller than that of child mortality. He also found that there is a notable variation across the states in the speed of mortality reductions: the fastest decline in mortality between 1951-1961 and 1971-1981 occurred in southern state of Karnataka, whereas the slowest progress during the same period was observed in eastern state of Orissa (Bhat, 1987).

The lack of studies on all-age and adult mortality in India and many other developing countries can be explained by several specific problems related to the registration of adult 
mortality. In general, reliable mortality statistics require fully functioning vital registration systems. However, the registers ensuring good coverage of vital events are missing in India (Malaker, 1986; Bhat, 1987). Therefore, retrospective demographic and health surveys have been seen as a good alternative for measuring mortality. However, these surveys may provide reliable information only about infant and child mortality, whereas obtaining information about adult deaths is often problematic. First, adult deaths are relatively rare events, and a big sample size is therefore needed for obtaining robust mortality estimates. Second, information about child deaths is mainly provided by their mothers or guardians. At the same time, information about adult deaths in some cases cannot be reported due to a lack of informant or may be reported by variety of informants which increases the probability of duplication and bias. Finally, it seems to be a lack of interest among researchers in India to explore possibilities of existing data and address the growing importance of mortality at adult ages.

The present study attempts to fill the knowledge gap by analyzing variation of mortality for a broad range of child and adult ages for the whole of India and for its states. The study uses data from the Sample Registration System (SRS) which is unique source of information providing representative and the most complete data on mortality across all ages in India (National Population Commission, 2001). We address data quality issues by performing systematic data plausibility checks and by comparing the SRS data to the respective figures from National Family Health Survey (NFHS) and other surveys. We also assess the accuracy of old age mortality estimates by fitting a parametric (Gompertz) mortality model. Second, we examine time trends in temporary life expectancy between the exact ages 0 and 60 in 16 states of India from the early 1970s until 2000-2004. Using dispersion measure of mortality and Gini coefficient, we analyze the changes in inter-regional variability over time. Finally, we estimate 
the contributions of child and adult mortality to the total changes in temporary life expectancy in different states of India.

\section{Data source}

The study is based on mortality estimates calculated from the Sample Registration System data. The system was initiated by the Office of the Registrar General, India with a goal to generate reliable and continuous data on demographic indicators. It was introduced as a pilot scheme in some selected states in 1964-65, the SRS was converted into a full scale system in 1969-70.

The SRS is based on a dual record system. It involves continuous enumeration of births and deaths in a sample of villages/urban blocks by a resident (part time) enumerator. In addition, at the end of each six months period, a retrospective survey is being conducted by a full time supervisor. The data obtained through these two sources are matched. The unmatched and partially matched events are re-verified in the field to obtain their unduplicated count. The advantage of this procedure, in addition to elimination of errors of duplication, is that it leads to a quantitative assessment of the sources of distortion in the two sets of records making it a self evaluating technique.

The sampling units of SRS are replaced periodically using the results of the latest census report. Once a sample unit is included in the system, a complete census is taken and this forms the baseline data for the sample population. In short, the sequence of the Sample Registration System is performed by completing the following steps:

- Baseline survey of the sample units to obtain usual resident population of the sample areas (population exposed to death)

- Longitudinal enumeration of vital events pertaining to usual resident population by the enumerator 
- Independent retrospective half-yearly surveys for recording births and deaths which occurred during the half-year under reference and up-dating the house list, household schedule and the list of women in the reproductive age group along with their pregnancy status by the supervisor

- Matching of events recorded during continuous enumeration and those listed in course of half-yearly survey

- Field verification of unmatched and partially matched events.

In order to check the quality of data from SRS, information from the Demographic and Health Survey of India, commonly known as National Family Health Survey (NFHS) is utilized in this paper (Macro Int. IIPS \& ORC Macro, 1995, $2000 \& 2007$ ). NFHS is a large scale, cross sectional, multi-round survey conducted in a nationally representative sample of households throughout India. The three rounds of NFHS have been conducted during 1992-93, 1998-99 and 2005-06 (IIPS 1995; IIPS \& ORC Macro, 2000; IIPS \& ORC Macro, 2007). In each state, the rural sample was selected in two stages, with the selection of Primary Sampling Units (PSUs), which are villages, with the probability of selection proportional to their population sizes (PPS) at the first stage, followed by a random selection of households within each PSU at the second stage. In urban areas, a three-stage procedure was performed; first, wards were selected with PPS sampling, secondly, one census enumeration block (CEB) was randomly selected from each ward and lastly, households were selected randomly within each selected CEB. The NFHS sample size varies from one round to another $(89,777$ ever-married women of age 13-49 in NFHS I; 91,000 ever-married women of age 15-49 in NFHS II; 124,385 ever-married women of age 15-49 and 74,369 men of age 15-54 in NFHS III). NFHS I and II collected information on mortality both from women and household questionnaires. Questionnaire for women asked all 
women of reproductive age to provide the following information for each live birth: sex, month and year of birth, current survival status of the child, and child's age at the time of the survey or child's age at death. This information was used to calculate the direct estimates of infant and child mortality. In addition, household questionnaire aimed at information about the deaths among usual residents which are taken place within two years before the survey. The household head or any other able adult member was responsible for providing information about the sex, age at death, date of death, and cause of death. The complete procedure for estimating death rates is described in the NFHS reports (IIPS, 1995; IIPS \& ORC Macro, 2000). The procedure was the same in case of the NFHS III for under-five mortality but this round of NFHS does not provide information on death among other members of the household. Thus given the difference in the methods and sample designs of SRS and NFHS, it is sensible to compare the mortality estimates provided by these two sources to check the concordance between them.

The region of residence in India has particular importance in the demographic performance of the residents. Appendix 3 summarizes certain socio-economic and demographic characteristics of the regions. Although Hindu and Muslim are two main religions at the national level, some states have also considerable percentages of population of other religions. The latter include Christianity, Sikh, Buddhism, Jain, and other. There is a significant variability according to religion across the states. For example, the percentage of Hindu population varies from 37 percent in Punjab to 95 percent in Himachal Pradesh. Variation in literacy rate is also very notable ranging from 47 percent in Bihar to 91 percent in Kerala. Scheduled Castes (SC) and Scheduled Tribes (ST) are Indian population groups that are explicitly recognized as socially disadvantaged groups of the society by the Constitution of India. This classification is based on ethnicity of the person and on the constitution of India that has given these castes special status 
for upward socio-economic mobility. Scheduled Castes (SC) and Scheduled Tribes (ST) together comprise over 24 percent of India's population. The populations of Madhya Pradesh and Orissa have higher percentages of these socially disadvantaged groups. Similarly, total fertility rates and infant mortality show considerably variation across the states. All southern states have reached below replacement level of fertility whereas states like Bihar and Uttar Pradesh are far higher than the replacement level. Infant mortality rates vary from 73 per 1000 live births in Uttar Pradesh to 15 per 1000 live births in Kerala in 2005-2006. Percentage of population living below the poverty line has also wide variation from five percent in Punjab to forty percent in Orissa (Appendix 3).

Further analysis will be considering 16 states of India representing the five major geographical regions of the country:

1) Haryana, Himachal Pradesh, Punjab, Rajasthan (North)

2) Uttar Pradesh, Madhya Pradesh (Center)

3) Assam, Bihar and West Bengal (East)

4) Gujarat and Maharashtra (West)

5) Andhra Pradesh, Karnataka, Kerala, and Tamil Nadu (South).

\section{Data quality}

\subsection{Coverage by the Sample Registration System}

Since the coverage by civil registration system is incomplete, sample registration system (SRS) is considered to be one of the most reliable systems for vital statistics for India (National Commission on Population, 2001). In the past, there have been some direct attempts to evaluate the completeness of vital events reported in the SRS by matching the events recorded in an 
intensive enquiry with those recorded in the regular phase. Results of such investigations conducted in 1980-81 suggested an omission rate for the whole India of 3.1 percent for births and 3.3 percent for deaths (RGI, India, 1983b). A similar enquiry conducted in 1985 suggested that omission rates decreased to 1.8 percent for births and 2.5 percent for deaths (RGI, India, 1988). The State level estimation of under-enumeration of vital events showed that underenumeration levels are relatively higher in Assam, Karnataka, Rajasthan and Uttar Pradesh. Unfortunately, since 1985, no direct attempt has been made to evaluate the completeness of the SRS.

Applying modified version of the Bennett-Horiuchi method, Bhat (2001) found that completeness of death registration above the age of 5 years has decreased from 99 percent for both sexes in 1971-81 to 87 percent for males and 86 percent for females in 1990-97. However, these findings were not confirmed by independent checks using growth rates of population censuses. A clear weakness of this study was induced by a strong assumption about absence of migration. The application of the generalized growth balance method is more justifiable in a country like India where population is yet to be stable and open for migration. The results based on this method suggest that overall completeness of death registration for all ages during 197180 was 94 percent for males and 91 percent for females (Bhat, 2002). The completeness varied across the states from a low of 84 percent among females in Karnataka to 100 percent among males in Kerala and Gujarat and females in Madhya Pradesh (Bhat, 2002).

During 1971-1991, the completeness of death registration among males remained stable at about the same level of 95 percent. But among females, the completeness deteriorated from about 91 percent in 1971-80 to 88 percent in 1981-91. The worsening in the quality of 
registration was more notable in Punjab, Haryana, and Uttar Pradesh in the northern part of India and in the western states of Gujarat and Maharashtra (Bhat, 2002).

\subsection{Plausibility of mortality estimates at different ages}

Considerable difference may exist in the degree of completeness of death registration by different age groups. As death of an adult member of a family usually cause serious consequences on the economic and psychological conditions on the remaining members of the family, the death registration at adult ages is generally sought as more reliable than in any other age group. On the other hand, for infant and child deaths good informants (mothers) are more readily available. As mentioned earlier, mortality rates for different age groups by sex and type of residence from SRS are being compared with the corresponding NFHS figures.

To evaluate the quality of data as a whole, it is very necessary to assess the completeness of infant and child death because registering a death during the early period of life is sensitive to various issues, for instance, restrictive definition of live birth, recall lapse in retrospective surveys, age misstatement, underreporting of deaths due to psychological reasons of parents etc. (Anderson and Silver, 1986). Some previous studies criticize the infant mortality from SRS during the early seventies (1972-74) because of misclassification of stillbirth and early neonatal death (Bhat, 1998). Table 1 depicts infant mortality rate by type of residence from the three rounds of National Family Health Survey and SRS during the period 1981-2006 (IIPS, 1995; IIPS \&ORC Macro, 2000; IIPS \& ORC Macro, 2007). The level of agreement in infant mortality between the SRS and NFHS appears to be good. The coverage of infant deaths seems to be more complete in SRS than in NFHS. The concordance level between these two sources is generally good over the period 1991-2006, with the only exception to the case of urban residents in 1996- 
2000. To better understand the concordance between the two sources in different geographical regions, we plotted infant mortality rates from SRS (2002-06) and NFHS III conducted in 200506. These rates refer to infant mortality during four years period before the survey for the fifteen major states in India (Figure 1).

It can be seen that for the most of the states (excluding Bihar, Kerala and West Bengal) infant mortality rates from SRS are slightly higher than the corresponding figures according to NFHS (Figure 1). This suggests that the SRS-based estimates of infant mortality are plausible. It can also be assumed that coverage of infant deaths across the states by SRS is as good as or even better than coverage by NFHS.

Figure 1 Comparison of infant mortality rates from NFHS III ${ }^{1}$ (for the period 2001-05) and SRS (2002-06), 16 states of India

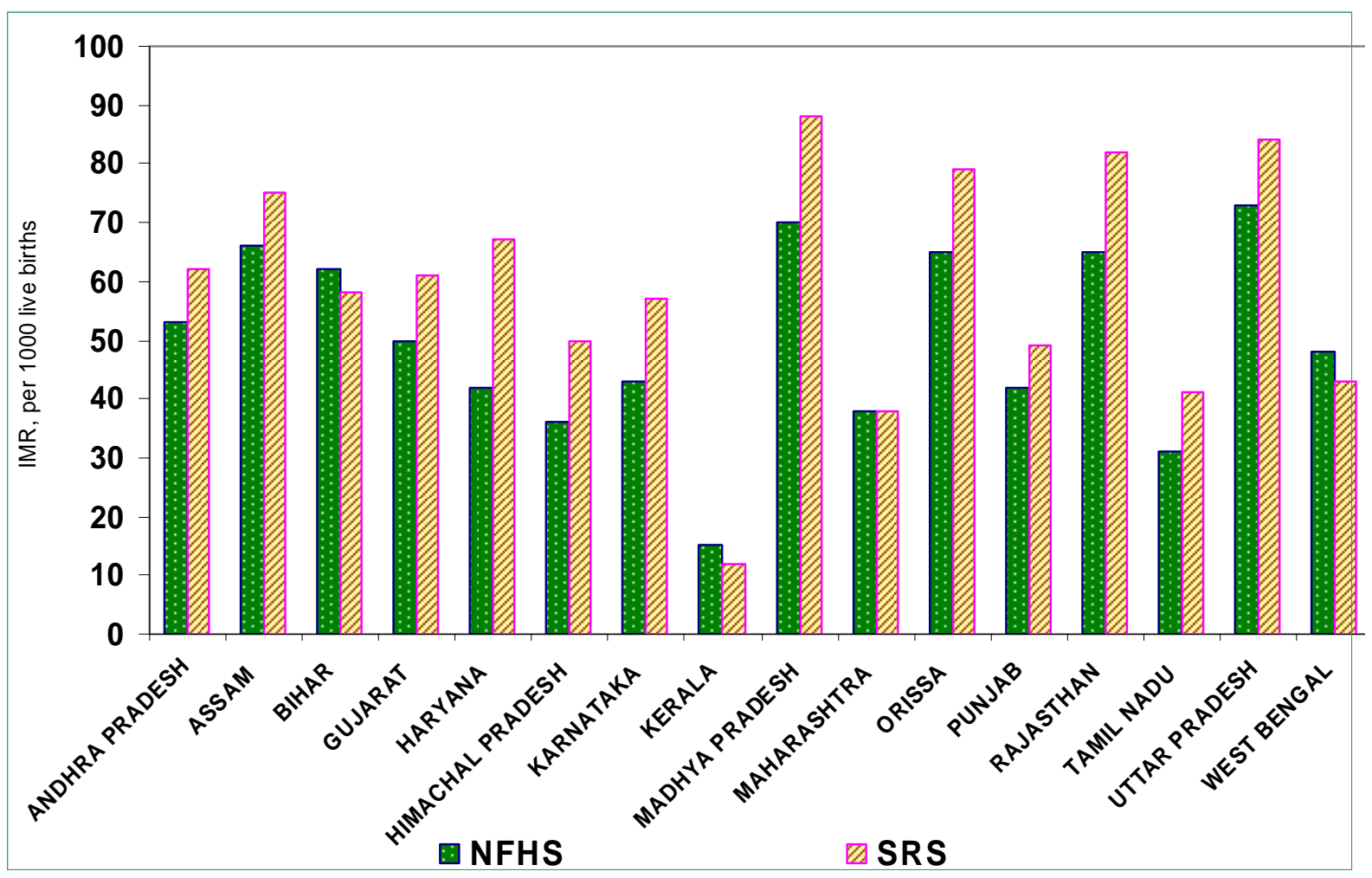

${ }^{1}$ NFHS infant mortality rates come from the NFHS III conducted 2005-06 and refer to infant mortality rates covering 0-4 years before the survey.

Sources: IIPS \& ORC Macro, 2007 and SRS based abridged life table, 2002-06. 
Table 1 Comparison of infant mortality rates between SRS and NFHS by type of residence (per 1000 live births)

\begin{tabular}{|c|c|c|}
\hline & NFHS & SRS \\
\hline & NFHS III (2005-06) & \\
\hline Place/Period & 2002-05 & 2002-06 \\
\hline Urban & 41 & 39 \\
\hline Rural & 62 & 69 \\
\hline \multirow[t]{2}{*}{ Total } & 57 & 62 \\
\hline & 1996-00 & $1996-00$ \\
\hline Urban & 55 & 45 \\
\hline Rural & 78 & 78 \\
\hline \multirow[t]{2}{*}{ Total } & 72 & 72 \\
\hline & 1991-95 & 1991-95 \\
\hline Urban & 53 & 53 \\
\hline Rural & 86 & 86 \\
\hline \multirow[t]{3}{*}{ Total } & 77 & 80 \\
\hline & NFHS II (1997-98) & \\
\hline & 1994-97 & 1995 \\
\hline Urban & 47 & 48 \\
\hline Rural & 73 & 80 \\
\hline \multirow{2}{*}{ Total } & 68 & 74 \\
\hline & 1989-93 & 1991-93 \\
\hline Urban & 51 & 50 \\
\hline Rural & 86 & 85 \\
\hline \multirow[t]{2}{*}{ Total } & 78 & 78 \\
\hline & 1984-88 & 1986-88 \\
\hline Urban & 65 & 61 \\
\hline Rural & 93 & 104 \\
\hline \multirow[t]{3}{*}{ Total } & 86 & 94 \\
\hline & NFHS I (1992-93) & \\
\hline & 1989-92 & 1991 \\
\hline Urban & 56 & 53 \\
\hline Rural & 85 & 87 \\
\hline \multirow[t]{2}{*}{ Total } & 79 & 80 \\
\hline & 1984-88 & 1985 \\
\hline Urban & 62 & 59 \\
\hline Rural & 103 & 107 \\
\hline \multirow[t]{2}{*}{ Total } & 94 & 97 \\
\hline & 1979-83 & 1981 \\
\hline Urban & 69 & 63 \\
\hline Rural & 111 & 119 \\
\hline Total & 101 & 110 \\
\hline
\end{tabular}


Comparisons of age-specific death rates between SRS and NFHS are given in Appendixes $1 \& 2$. Once again, there is a good concordance between the two sources. In addition, the coverage of SRS seems to be better for most of the age groups. The disagreement between the two sources becomes visible only after the age 60 .

Like in other developing countries, age misreporting is quite common in India (Bhat, 1987). As far as census data are concerned, age misstatement is the most important problem for application of indirect estimation methods in India (Bhat, 1987). This is because most Indians have imprecise knowledge of their age and what gets recorded in a census is usually an educated guess of enumerator and/or of the respondent. Analysis of age distributions of population counts according to the census and according to the SRS shows that age exaggeration is more common among males than females. On the contrary, females are more likely to understate their age (Bhat, 1987).

Previous studies found discrepancy of age distributions between SRS and censuses; in particular, the age distributions by SRS show significantly lower proportions of population at old ages (Bhat, 1987). Bhat (1987) explains this discrepancy by several factors such as sampling and other errors. Qualitative difference in age reporting between the SRS baseline survey and censuses is the most probable cause leading to this discrepancy. Numerous checks of plausibility of age distributions suggest that the SRS data are more reliable (Bhat, 1987).

\subsection{Plausibility of old age mortality estimates: a comparison with the Gompertz curve}

There is much direct and indirect evidence that ages of older persons tend to be misreported in both census and death records. The ages of older people are more likely to be exaggerated rather than understated resulting in too high proportions of survivors to the oldest 
ages. This, in general, leads to underestimation of mortality rates at old ages and in turn, overestimation of expectation of life, unless ages at death are exaggerated considerably more than ages of living persons, and thus tend to inflate mortality (Horiuchi \& Coale, 1982).

This may be true in the case of SRS data as it is evident that SRS old age mortality is lower in comparison to NFHS old age mortality (Appendix 1 \& 2). It can be seen that age specific mortality rates at young and adult ages are almost identical in both sources. However, old age mortality estimates by SRS are still lower than corresponding figures by NFHS. The study by Bhat (1995) indicated that SRS reports fewer survivors to older ages.

It is, therefore, decided to evaluate the quality of the SRS data on old age by applying a parametric model of mortality curve. One of the widely used laws of mortality is Gompertz's law which assumes that the susceptibly to death exponentially increases with age:

$$
\mu(x)=R \cdot e^{a x}
$$

where $R$ is a baseline level of mortality and $\alpha$ is the steepness of mortality increase with age. We use the range of ages $35-60^{1}$ to estimate the two parameters of model (1) for males and females separately for the national and sub-national populations from 1971-75 to 2000-04.

\footnotetext{
${ }^{1}$ We also experimented with other age ranges (e.g. 40-59 years, 55-69 years, or etc.) but got the same results.
} 
Figure 2 Application of Gompertz Curve on SRS Data Male and Female for All India, 1981-85 and 2000-04
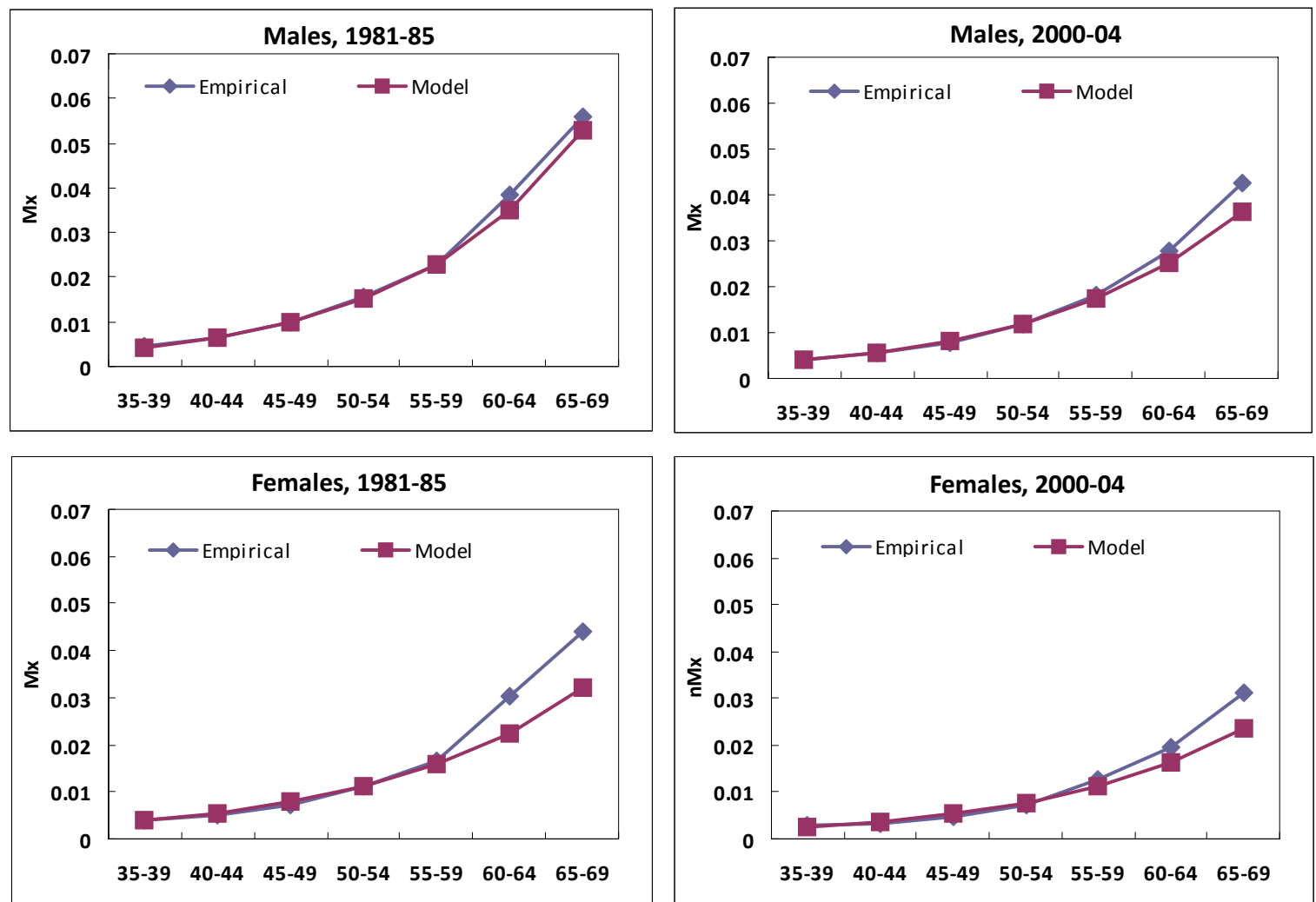

Sources: own estimates based on the SRS based abridged life tables, 1981-85 \& 2000-04.

Figure 2 shows that original male and (especially) female mortality estimates at ages 60 years and older remain higher than Gompertz model-based estimates. One possible reason behind this unexpected pattern for females is age understatement and undercount of older females in the SRS data (Bhat, 1995). All these factors may have contributed towards overstatement of mortality at older ages. Taking into account aforementioned data problems, we restrict our analyses to the age range 0 to 59 years. 


\section{Methods}

\subsection{Temporary life expectancy}

Life expectancy is the most widely used aggregated mortality measure in public health research. As we showed, the precision of life expectancy estimates based on the SRS data can be affected by errors in the old age which makes estimates of overall life expectancy at birth questionable. Arriaga (1984) showed that such problems can be avoided by the use of temporary life expectancies (or life expectancies between two specific ages). Following this idea, we compute temporary life expectancies between the exact ages 0 and 60 :

$$
e_{0 / 60}=\frac{T_{0}-T_{60}}{l_{0}}
$$

where $l_{0}$ is the radix of the life table, $T_{0}$ and $T_{60}$ are the numbers of person-years lived after ages 0 and 60 , respectively. While life expectancy at birth depends on mortality rates over the whole age range of ages (including age over 60 years), the temporary life expectancy depends on mortality rates between the exact ages 0 and 60 .

\subsection{Absolute and relative dispersion measures of mortality}

Dispersion measure of mortality is defined as the average absolute inter-population life expectancy difference between all pairs of populations, weighted by their sizes (Shkolnikov et al., 2003, Moser et al, 2005). Decrease and increase in $D M M$ show changes in absolute inequality among the states expressed in years of human life, respectively.

Following Moser et al. (2005), we compute DMM for 16 states of India applying on $\mathrm{e}_{0 / 60}$ : 


$$
D M M=\frac{1}{2}\left[\sum_{i} \sum_{j} p_{i} p_{j}\left(e_{0 / 60}^{i}-e_{0 / 60}^{j}\right)\right],
$$

where indexes $i, j$ run across the states, $1 \leq i, j \leq 16, e_{0 / 60}^{i}$ is temporary life expectancy of state $i$, and $p_{i}$ are the population weights of the states $i, \sum_{i} p_{i}=1$.

Another measure that we use to assess the relative inter-regional inequality in longevity in India is Gini coefficient $(G) . G$ is a measure of relative inequality that is equal to DMM divided by the average life expectancy (Shkolnikov et al. 2003):

$$
G=\frac{D M M}{\overline{e_{0 / 60}}} \text {, where } \overline{e_{0 / 60}}=\left[\sum_{i} p_{i} e_{0 / 60}^{i}\right] \text {. }
$$

\subsection{Method of decomposition of temporary life expectancy by age}

The method for discrete age decomposition of differences between two life expectancies by age was developed independently in the 1980s by the three researchers from Russia, the USA, and France (Andreev, 1983; Arriaga 1984; Pressat, 1985; Andreev et al., 2002). The decomposition of temporary life expectancy by age between the exact ages 0 and 60 can be expressed as:

$$
\begin{gathered}
e_{x / 60}^{2}-e_{x / 60}^{1}=\frac{1}{l_{0}} \sum_{i} \delta_{i} ; \\
\delta_{i}=\frac{1}{2}\left[r_{x_{i}}^{2}\left(e_{x_{i} / 60}^{2}-e_{x_{i} / 60}^{1}\right)-l_{x_{i+1}}^{2}\left(e_{x_{i+1} / 60}^{2}-e_{i+1}^{1} / 60\right)\right]- \\
-\frac{1}{2}\left[l_{x_{i}}^{1}\left(e_{x_{i} / y}^{1}-e_{x_{i} / 60}^{2}\right)-l_{x_{i+1}}^{1}\left(e_{x_{i+1} / 60}^{1}-e_{i+1}^{2} / 60\right)\right]
\end{gathered}
$$

where $\mathrm{i}=1,2,3, \ldots, 13 ; x_{1}=0, x_{2}=1, x_{i}=(i-2) \cdot 5$ (for $\left.i \geq 3\right)$. 


\section{Results}

\subsection{Changes in temporary life expectancy}

Figure 3 depicts trends in temporary life expectancy for the total, urban, and rural populations of India. First, it is interesting to notice the fact that for the total population, female disadvantage against males is observed throughout the whole period 1971-2004 with the only exception to 1986-90. The female longevity disadvantage is especially pronounced and still persisting in the rural areas and may be attributed to higher level of female child and maternal mortality (R.G.I. 2006). At the same time, Indian urban females had much smaller disadvantage in the early 1970 s and catch up with males in the first half of the 1980s. Since then, females in urban areas have been maintaining a small longevity advantage as compared to males.

Fig. 3 Trends in temporary life expectancy between exact ages 0 and 60 in India, 1971-75 to 2000-04.
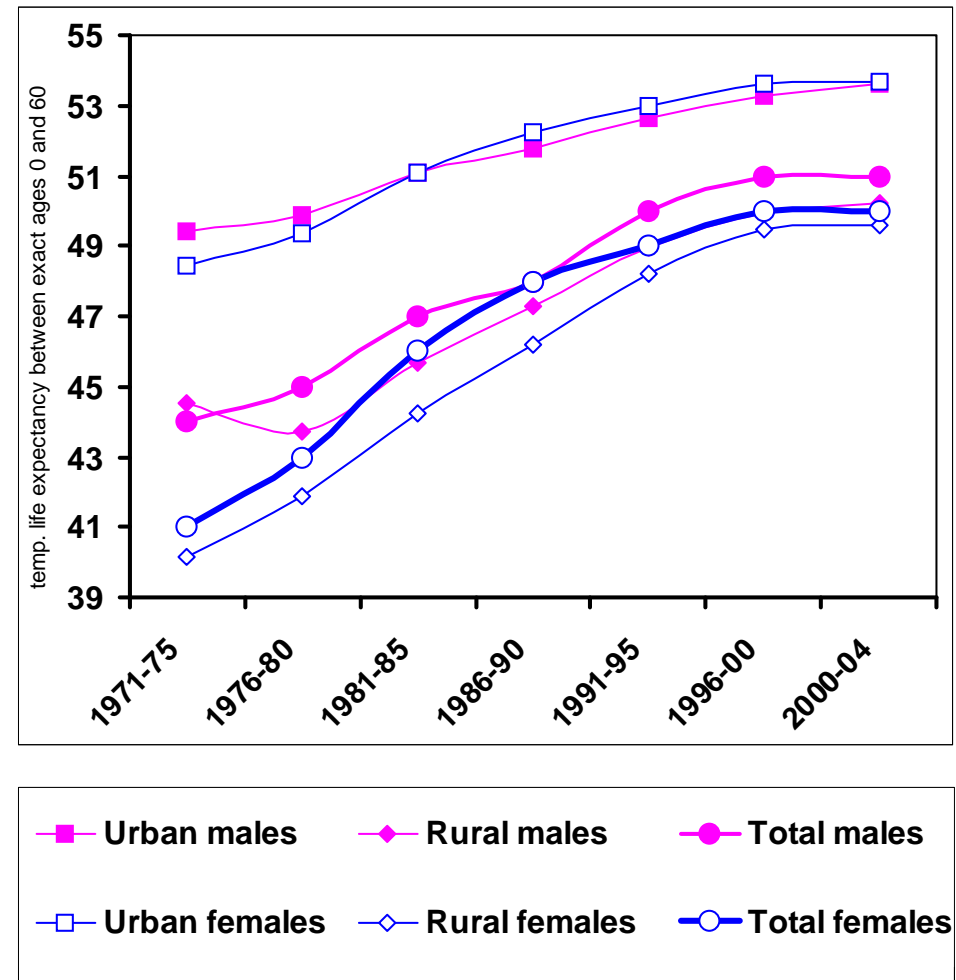
Figure 4 and Appendix 4 show trends in temporary life expectancy from 1971-75 to 2000-04. It is evident that temporary life expectancy has been increasing over the time for both sexes in all states. However, the pace of increase is different in different decades. The situation has been rapidly improving until the early 1990s. Later on in the late 1990s and the early 2000s, there was a slow down or even stagnation in some studies (Figure 4).

Figure 4. Trends in temporary life expectancy between exact ages 0 and 60 in the 16 states of India, 1971-75 - 2000-04.
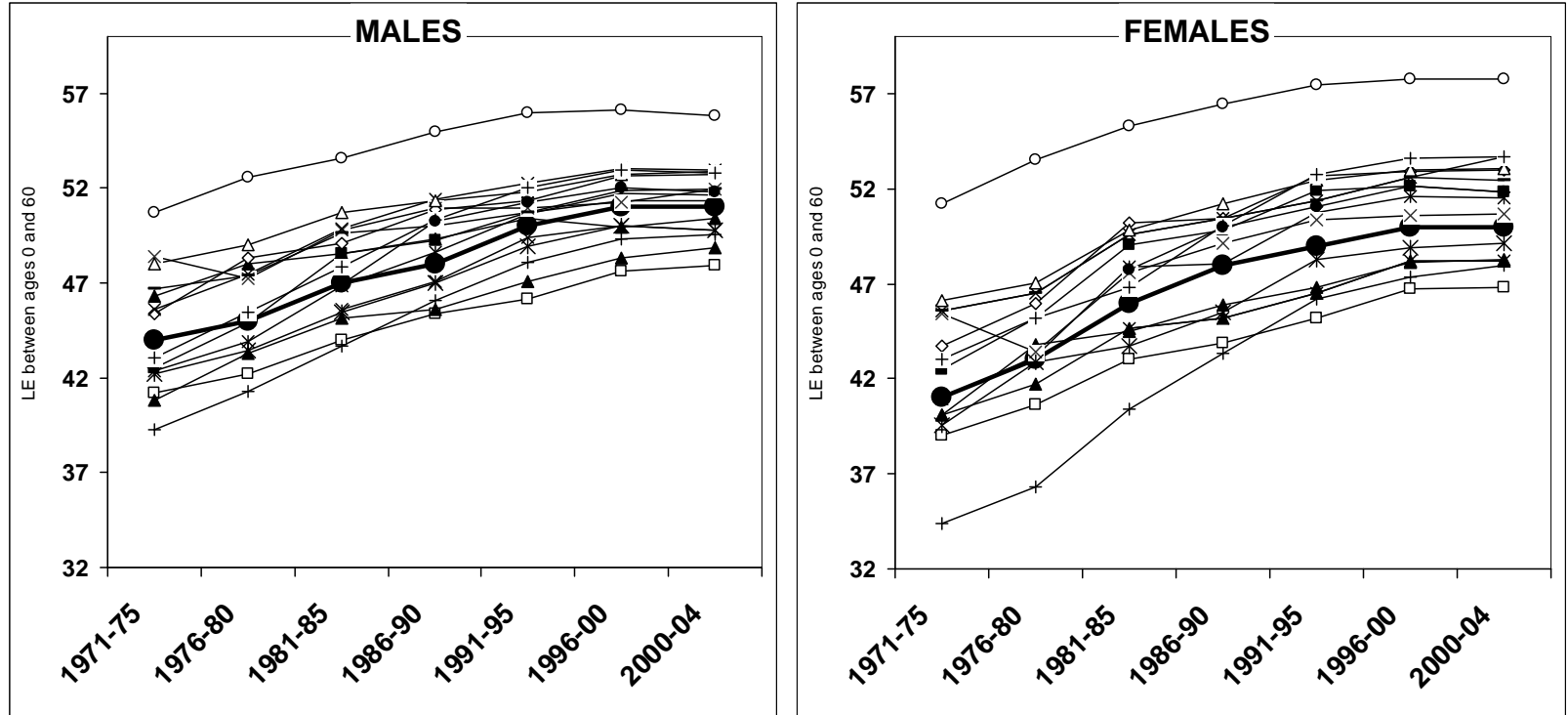

\begin{tabular}{|c|c|c|c|c|}
\hline$\rightarrow$ India & $\rightarrow$ - Andhra Pradesh & $\neg$ Assam & $\times$ Bihar & * Gujarat \\
\hline$-\times-$ Haryana & $\prec$ Himachal Pradesh & — Karnataka & -ం-Kerala & $*$ Maharashatra \\
\hline$\neg-$ Madhya Pradesh & $\dashv$ Orissa & $\triangle$ Punjab & * Rajasthan & -+- Tamil Nadu \\
\hline 1 Uttar Pradesh & $\multimap$ West Bengal & & & \\
\hline
\end{tabular}

There are important regional peculiarities in the life expectancy trends. Kerala's outstanding performance in terms of temporary life expectancy was observed throughout the whole period. The Kerala phenomenon has been extensively discussed in literature (Sen, 1993, 1998, 2001; Caldwell, 1986; Bhat \& Rajan, 1990; Nag, 1983) and we will not focus on it here. Despite the fact that temporary life expectancy for Uttar Pradesh was the lowest throughout the 
period 1971-90, the improvements in this state (especially for females) were much steeper than in another poorly performing state, Madhya Pradesh.

Another important point is the convergence of temporary life expectancy among states with time. The gap between regions with the highest and lowest male temporary life expectancies has dropped from 11.4 years in 1971-75 to 7.9 years in 2000-04. Throughout the whole period, the equivalent gap for females was greater than that for males. However, Indian females experienced also a faster reduction of the gap from 16.8 years in 1971-75 to 11.0 years in 2000-04.

In contrast to the max-min gap, DMM and Gini measures account for mortality in every region and for their population sizes. Table 2 shows values of the two measures of absolute life expectancy inequality at different time points. Between 1971-1975 and 2000-2004, both measures have decreased by about one half suggesting a radical reduction of the inter-state inequality in the face of death.

Table 2. Gini coefficient and dispersion measure of mortality for age group 0-59 in India in $1971-2004$.

\begin{tabular}{lcccc}
\hline & \multicolumn{2}{c}{ Male } & \multicolumn{2}{c}{ Female } \\
\hline Year & Gini (in percent) & DMM (in years) & Gini (in percent) & DMM (in years) \\
$1971-75$ & 4.1 & 1.75 & 6.1 & 2.51 \\
$1981-85$ & 3.1 & 1.46 & 4.5 & 2.05 \\
$1991-95$ & 2.4 & 1.19 & 3.4 & 1.69 \\
$2000-04$ & 1.9 & 0.96 & 2.9 & 1.49 \\
\hline
\end{tabular}




\subsection{Geographical pattern of temporary life expectancy}

After the just described long term convergence, inter-regional differences in temporary life expectancy in 2000-2004 still remained very substantial (7.9 and 11.0 years for males and females, respectively). Figure 5 shows geographical patterns of the male and female temporary life expectancies in 2000-2004. The north-south differential is the most important regularity on both maps. Life expectancy tends to be lower in the states situated in the north and north-east of the country and higher in the south and south-west. The northern states of Himachal Pradesh and Punjab constitute a notable exception. The observed tendency is quite similar to the one described by Bhat twenty years ago (Bhat, 1987) suggesting that in spite of the convergence relative positions of the states have not changed much.

Figure 5. Temporary life expectancy between exact ages 0 and 60 for Indian states in 2000-2004
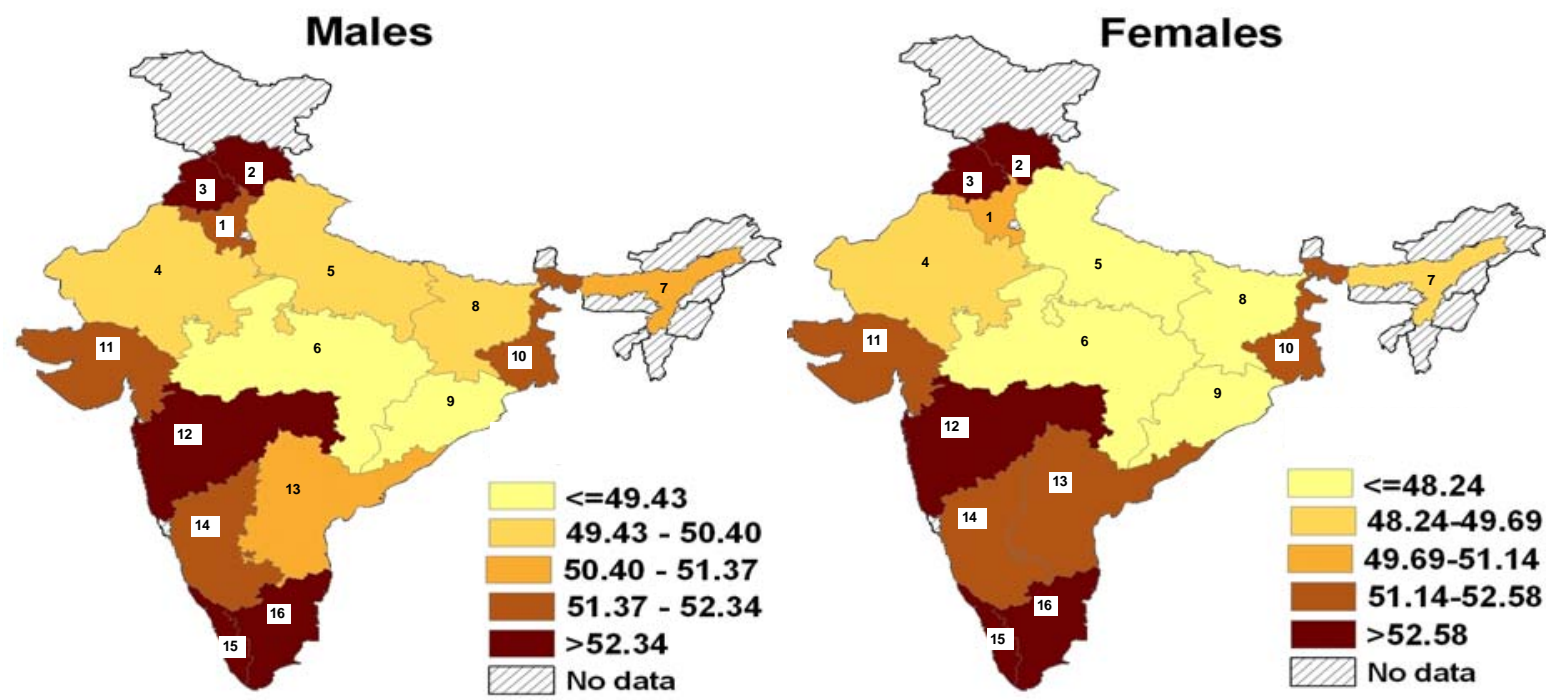

Abbreviations: 1- Haryana, 2- Himachal Pradesh, 3- Punjab, 4 - Rajasthan, 5 - Uttar Pradesh, 6 - Madhya Pradesh, 7

- Assam, 8 - Bihar, 9 - Orissa, 10 - West Bengal, 11 - Gujarat, 12 - Maharashtra, 13 - Andhra Pradesh, 14 - Karnataka, 15 - Kerala, 16 - Tamil Nadu. 


\subsection{Contributions of child and adult mortality to increase in the temporary life expectancy}

Results of age decomposition of changes in temporary life expectancy between 19711975 and 1986-1990 and between 1991-1995 and 2000-2004 are depicted in Figures 6 and 7. We show only contributions of mortality changes in the two broad age groups of children aged 0 to14 and adults aged 15 to 59 .

One immediate inference can be drawn: an overwhelming part of the total growth of temporary life expectancy is attributable to reduction of child mortality. With a few exceptions (males in Kerala and females in Andhra Pradesh and Haryana from 1991-95 to 2000-04), contributions of child ages are positive for all states irrespective of sex and time period. The second important point is that the gain in temporary life expectancy is much more important for the first than for the second period. From 1971-75 to 1986-1990, the increases in temporary life expectancy were 4.9 and 6.1 years among males and females, respectively. For the period between 1991-1995 and 2000-2004, the gains constituted only 1.2 years for both sexes. These low values tell about a significant slow down in the positive health trend. Appendixes $5 \mathrm{a}$ and $5 \mathrm{~b}$ allow to trace the slowing down trend of mortality reduction by looking at the state- and periodspecific values of probabilities of dying within the ranges of child and adult ages.

Decomposition analysis reveals that the diminishing contributions of younger ages are the main reason of such slow down in temporary life expectancy (Figures 6 and 7). The declining contribution of younger ages can be explained by the fact that infant and child mortality has reached the levels beyond which further reduction is unattainable without very substantial improvement in health care and living conditions. 
Figure 6. Decomposition of changes in temporary life expectancy between exact ages 0 and 60 by two broad age groups for India and its states: 1971-1975 to 1986-1990.
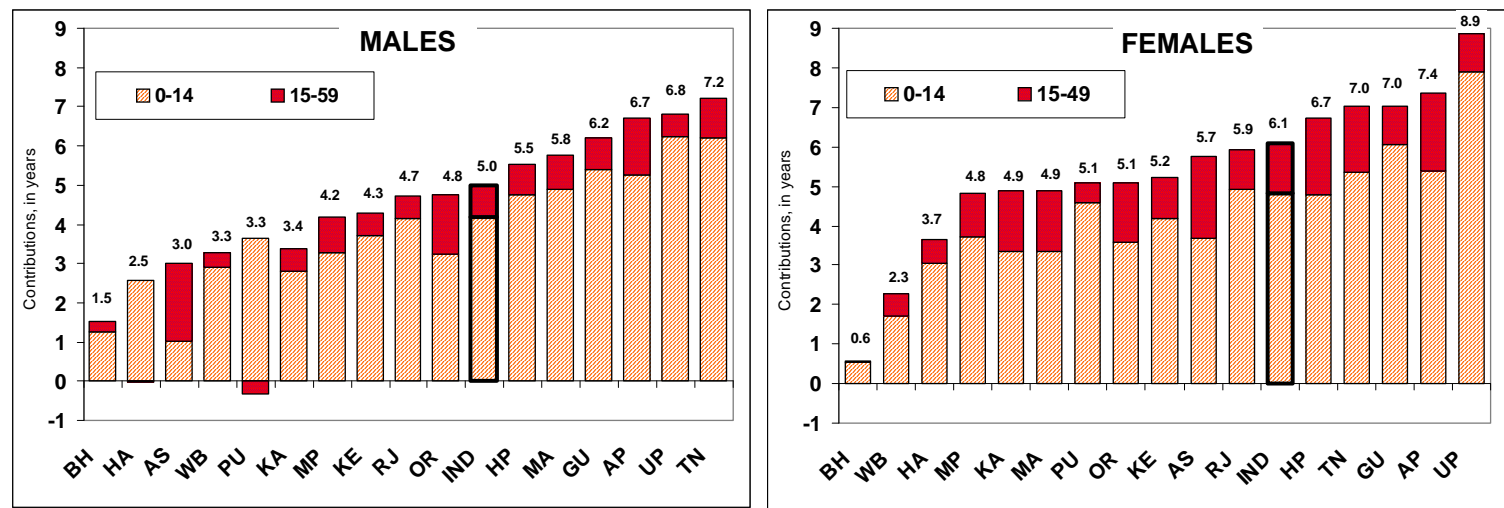

Notes: 1. Total gains in temporary life expectancy are shown above each bar. 2. Decomposition for Bihar and West Bengal states was performed for the period from 1981-85 to 1986-90.

Abbreviations: AP - Andhra Pradesh, AS - Assam, BH - Bihar, GU - Gujarat, HA- Haryana, HP - Himachal Pradesh, KA Karnataka, KE - Kerala, MP - Madhya Pradesh, MA - Maharashtra, OR - Orissa, PU - Punjab, RJ - Rajasthan, TN - Tamil Nadu, UP - Uttar Pradesh, WB - West Bengal.

Figure 7. Decomposition of changes in temporary life expectancy between exact ages 0 and 60 by two broad age groups for India and its states: 1991-1995 to 2000-2004.
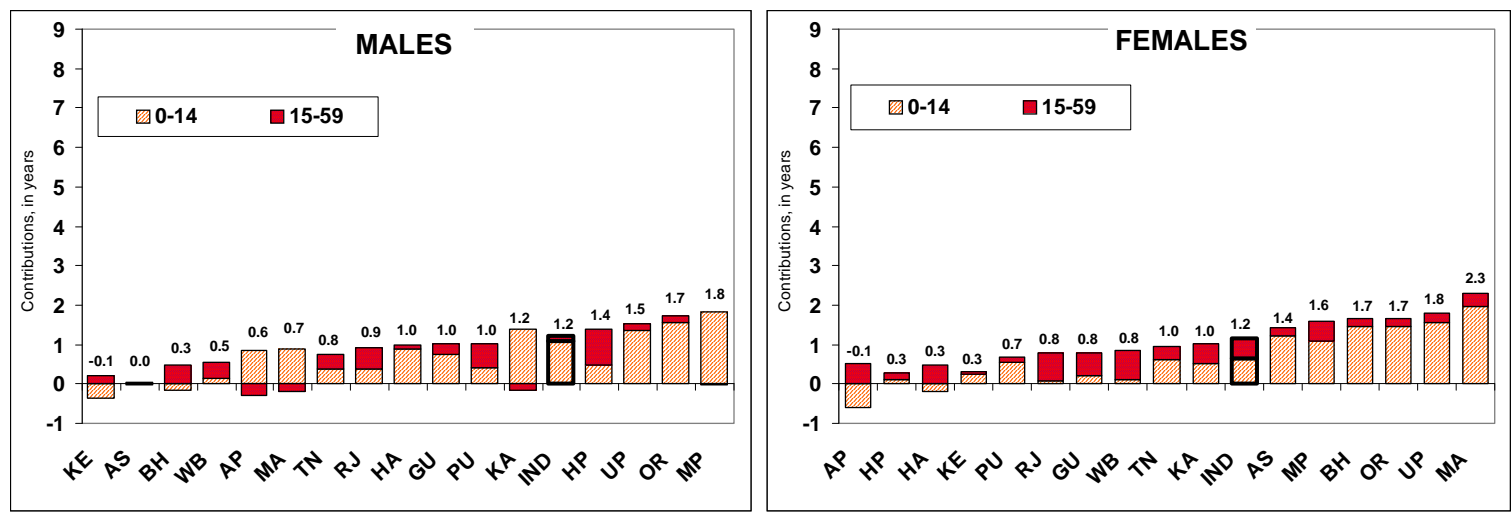

Notes: 1. Total gains in temporary life expectancy are shown above each bar. 2. Decomposition for Bihar and West Bengal states was performed for the period from 1981-85 to 1986-90.

Abbreviations: AP - Andhra Pradesh, AS - Assam, BH - Bihar, GU - Gujarat, HA- Haryana, HP - Himachal Pradesh, KA Karnataka, KE - Kerala, MP - Madhya Pradesh, MA - Maharashtra, OR - Orissa, PU - Punjab, RJ - Rajasthan, TN - Tamil Nadu, UP - Uttar Pradesh, WB - West Bengal.

Similarly to the young age group, the positive contributions of adult age group have also declined in the second period. It is interesting to note that although the contribution of ages 15 to 59 to the increase in female temporary life expectancy is positive during the whole period of 
observation for all states (which may be the result of improvements in maternal mortality), the equivalent figures for males appeared to be negative in some states such as Andhra Pradesh, Karnataka, and Maharashtra. This fact could be indicating a possible negative effect of growing prevalence of HIV among male adults since these states experienced the highest HIV prevalence in the antenatal care population in 2005. (NACO, 2006; IIPS and Macro, 2007). According to the NFHS III report, the HIV prevalence rate among male adults of age 15-49 is much higher than that among their female counterparts (IIPS \& ORC Macro, 2007).

Probabilities of dying for the age ranges 0 to 15 and 15 to 60 in 2000-2004, given in Appendixes 5a and 5b, suggest certain difference between geographic patterns of child and adult death in India. While mortality at ages under 15 represents essentially the north-south differential described in previous section, adult mortality represents a less clear pattern with signs of an eastwest differential. Probabilities of dying of adults are higher in the states of the north-east and center-east. For females, higher levels of adult mortality are observed in Uttar Pradesh, Bihar, Assam, Madhya Pradesh, and Orissa. For males, higher adult mortality is observed in Uttar Pradesh, Madhya Pradesh, Assam, Orissa, Maharashtra, and the southern state of Karnataka. If a steep decrease of infant mortality resumes in the future, importance of adult-age mortality for the overall health will grow.

\section{Summary}

This study examined trends in temporary life expectancy and mortality in India and its regions. This is a challenging task due to the absence of fully functioning vital registration system in the country. Therefore, we used data from the Sample Registration System which provides the most complete and representative data on mortality in India (National Commission 
on Population, 2001). Although some studies based on indirect methods suggest that there is some variation in completeness of the SRS coverage, the completeness of the SRS is generally high. However, we showed that even these data may be suffering from some deficiencies such as significant age misreporting and possible undercount of females at older ages. At the same time, the comparisons between the SRS and alternative sources (NFHS) suggested that the SRS estimates are likely to be accurate for children and adult ages. Thus, we assumed that restricting our analyses to the range of ages from 0 to 59 would allow us avoid significant data quality problems. Therefore, we believe that our analyses describe the major regularities of variation in health correctly. However, it is still worth to undertake more in-depth and systematic studies and checks for assessing the quality of the SRS data across the regions of India.

Temporary life expectancy between the exact ages 0 and 60 years was used to examine trends in life expectancy and mortality in India and its states. We generally observed an increase in temporary life expectancy for all states. Our study revealed also that temporary life expectancy has been converging across the states with time. This is mostly attributable to slower improvements in the states having initially higher longevity levels. However, we also identified important differences in the pace of improvement between the states and across time periods. It is worrying that after a spectacular progress during the 1970 s and the 1980 s, improvements in longevity have very much slowed down in the 1990s and 2000s.

The increases in temporary life expectancy in all states were mostly determined by contributions of mortality among infants and children. The contributions of mortality reductions at adult ages were generally smaller. Both contributions of the young and adult ages have declined since the 1990s. It means that mortality tends to stabilize at rather high level. This worrying fact requires further attention of researchers and policy makers as a matter of priority. 
Another important issue is persisting female health disadvantage which is particularly notable in rural areas and in some states.

The trends in temporary life expectancy for India and its states, and, especially, the recent slow down in improvements, leads to some general and more specific questions. First of all, it is necessary to examine causes of death that stand behind the observed slowing down of the progress and to evaluate the scale of the newly emerging health threats such as AIDS, returning infectious disease, and growing burden of chronic diseases and injuries. It is important to understand where is India going in terms of the stages of epidemiologic transition? It seems that India can be facing now a difficult transition from fight with traditional infectious diseases of childhood that were treated by simple and relatively inexpensive means such as sanitation and hygiene, vaccination, and drug therapy to a struggle with health problems of adulthood that are much more difficult to treat or prevent. Public health research should focus on identifying deficiencies and adverse conditions that prevent India from realizing its rapidly growing economic potential in further improvement of health of its population.

\section{Acknowledgements}

Ms. Nandita Saikia would like to express her gratitude to International Max Planck Research School for Demography and the Max Planck Institute for Demographic Research in Rostock (Germany) for providing all necessary support while preparing the paper. All authors would like

to thank Dr. Evgueni M. Andreev (Max Planck Institute for Demographic Research) for his useful comments and suggestions. 


\section{References}

Anderson, B.A., Silver, B.D. (1986). Infant mortality in the Soviet Union: regional differences and measurement isssues. Population and Development Review, Vol. 12(4), pp. 705-738.

Andreev, E.M. (1982). Metod komponent v analize prodoljitelnosty zjizni. [The method of components in the analysis of length of life]. Vestnik Statistiki, Vol. 9, pp. 42-47.

Andreev, E.M., Shkolnikov, V., Begun, A. Z. (2002). Algorithm for decomposition of differences between aggregate demographic measures and its application to life expectancies, healthy life expectancies, parity-progression ratios and total fertility rates. Demographic Research, Vol. 7, pp. 499-522.

Arokiasamy, P. (2004). Regional patterns of sex bias and excess female child mortality in India. Population, Vol. 59, pp. 831-863.

Arriaga, E.E. (1984). Measuring and explaining the change in life expectancies. Demography, Vol. 21(1), pp. 83-96.

Bhat, M.P. (1987). Mortality in India: levels, trends, and patterns. A dissertation in demography. Ann Arbor, Michigan: UMI.

Bhat, M.P. (1995). Age misreporting and its impact on adult mortality estimates in South Asia. Demography India, Vol. 24(1), pp. 59-80.

Bhat, M.P. (1998). Demographic estimates of post independence India: A new integration. Demography India, Vol. 27(1), pp. 23-37.

Bhat, M.P. (2001). Recent trends in fertility and mortality in India: critical reappraisal of data from sample registration system and national family health surveys. In: Population and development nexus in India: challenges for the New Millennium 2001. Eds.: K. Srinivasan and M. Vlassoff. New Delhi: Tata McGraw-Hill.

Bhat, M.P. (2002). Completeness of India's Sample Registration System: an assessment using the General growth-balance method. Population Studies, Vol. 56(2), pp. 119-134.

Bhat, M.P., Rajan, S.I. (1990). Demographic Transition in Kerala Revisited. Economic and Political Weekly, Vol. 25, No. 35/36, pp. 1957-1980.

Caldwell, J.C. (1986). Routes to low mortality in poor countries. Population and Development Review, Vol. 12, No. 2, pp. 171-220

Dyson, T., Moore, M. (1983). On kinship structure, female autonomy, and demographic behavior in India. Population and Development Review, Vol. 9(1), pp. 35-60.

Hayes, R., Mertens,T., Lockett, G. Rodrigues, L. (1989). Causes of adult deaths in developing countries: a review of data and methods. Washington, DC: World Bank, Population and Human Resources Department.

Horiuchi, Sh., Coale, A.J. (1982). A simple equation for estimating the expectation of life at old ages. Population Studies, Vol. 36(2), pp. 317-326.

India, Registrar General (India, R.G.) (1983b). Report on intensive enquiry conducted in subsample of SRS units, (1980-81). Occasional Paper No 2of 1983. Delhi: Controller of Publication. 
India, Registrar General (India, R.G.) (1988). Report on intensive enquiry conducted in subsample of SRS units. Occasional Paper No 1 of 1988. Delhi: Controller of Publication.

India, Registrar General (India, R.G.) (2006). Maternal mortality in India: 1997-2003. Trends, causes and risk factors. Report on collaboration with Center for Global Health Research, University of Toronto (Canada). New Delhi: India, R.G.

International Institute for Population Sciences (IIPS) (1995). National Family Health Survey 1992-1993, India. Mumbai, India: International Institute for Population Sciences (IIPS) / ORC Macro International.

International Institute for Population Sciences (IIPS) (2000). National Family Health Survey 1998-1999. Mumbai: International Institute for Population Sciences (IIPS) / ORC Macro International.

International Institute for Population Sciences (IIPS) (2007). National Family Health Survey 2005-2006, India. Mumbai, India: International Institute for Population Sciences (IIPS) / ORC Macro International.

Lopez, A.D., Caselli, G., Valkonen, T. (1995). Moving from description to explanation of adult mortality: issues and approaches. In: Adult Mortality in Developing Countries: From Description to Explanation. Eds.: G.Caselli, T.Valkonen, A.D. Lopez. Oxford: Clarendon Press.

Malaker, C.R. (1986). Estimation of adult mortality in India: 1971-81. Demography India, Vol. 15(1), pp. 126-135.

Marmot, M. (2005). Social determinants of health inequalities. Lancet, Vol. 365, pp. 1099-1104.

Murthi, M., Guio, A.-C., Dreze, J. (1995). Mortality, Fertility, and Gender Bias in India: A District-Level Analysis. Population and Development Review, Vol. 21, No. 4, pp. 745-782.

Moser, K., Shkolnikov, V.M., Leon, D.A. (2005). World mortality 1950-2000: divergence replaces convergence from the 1980s. Bulletin of World Health Organisation, Vol. 83(3), pp. 202-209.

Namboodiri, K., Suchindran, C.M. (1987). Life table techniques and their applications. Florida: Academic Press Inc.

Nag, M. (1983). Impact of Social and Economic Development on Mortality: Comparative Study of Kerala and West Bengal. Economic and Political Weekly, Vol. 18, No. 19/21, pp.877-900.

National Commission on Population (2001). Report of the Working Group on registration of births, deaths, and marriages. New Delhi: National Commission on Population.

Office of the Registrar General and Census Commissioner (2001). Census of India, 2001. New Delhi: Office of the Registrar General.

Pandey, A., Choe, M.K., Sahu, D., Luther, N.Y., Chand, J. (1998). Infant and child mortality in India. In: National Family Health Survey Subject Reports. Mumbai (India), Hawaii (USA): International Institute for Population Sciences, East-West Center Program on Population.

Pressat, R. (1985). Contribution des écarts de mortalité par âge à la différance des vies moyennes. Population, Vol. 4-5, pp. 766-770.

Sen, A. (1993). Positional objectivity. Philosophy and Public Affairs, Vol. 22, No. 2, pp. 126-145. 
Sen, A. (1998). Mortality as an indicator of economic success and failure. The Economic Journal, Vol. 108, pp. 1-25.

Sen, A. (2001). Health equity: perspectives, measurability, and criteria. In: Challenging inequities in health: from ethics to action. Eds.: T. Evans, M. Whitehead, F. Diderichsen, A. Bhuiya, M. Wirth. Oxford: Oxford University Prss.

Shkolnikov, V.M., Andreev, E., Begun, A.Z. (2003). Gini coefficient as a life table function: computation from discrete data, decomposition of differences, and empirical examples. Demographic Research, Vol. 8, pp. 306-357.

SRS based abridged life tables 1970-75: Census of India 1981 Occasional papers No. 1 of 1984, 1986, India (govt. of) Home Affairs (Min. of) Office of the Registrar General: Office of the R.G., New Delhi.

SRS based abridged life tables 1976-80: Census of India 1981 - Occasional papers No.1 of 1985, 1986, India (govt. of) Home Affairs (Min. of) Office of the Registrar General: Office of the R.G., New Delhi.

SRS based abridged life tables 1981-85: Census of India 1981 Occasional papers No. 1 of 1989, 1989, India (govt. of) Home Affairs (Min. of) Office of the Registrar General: Office of the R.G., New Delhi.

SRS based abridged life tables 1986-90: Occasional paper no. 1 of 1994, 1994, India, Registrar General:Vital Statistics Division, New Delhi.

SRS based abridged life tables 1990-94 and 1991-95 - SRS analytical studies report No. 1 of 1998, 1998, India: Registrar General Controller of Publications, New Delhi.

SRS based abridged life tables 1996-2000 and 1997-2001, 2004, India, Registrar General: Controller Of Publications, New Delhi.

SRS based abridged life tables 2000-2004: SRS Analytical Studies Report No. 1 of 2007, 2007 India, Registrar General India: Controller of Publications, New Delhi.

SRS based abridged life tables 2002-2006, 2007, India, Registrar General India: Registrar General, New Delhi.

Subramanian, S.V., Nandy, S., Irving, M., Gordon, D., Lambert, H., Smith, G.D. (2006). The mortality divide in India: The differential contributions of gender, caste, and standard of living across the life course. American Journal of Public Health, Vol. 96(5), pp. 818-825. 
Appendix 1. Comparison of age specific death rates between NFHS I (1991-92) and SRS (1991-92) for India
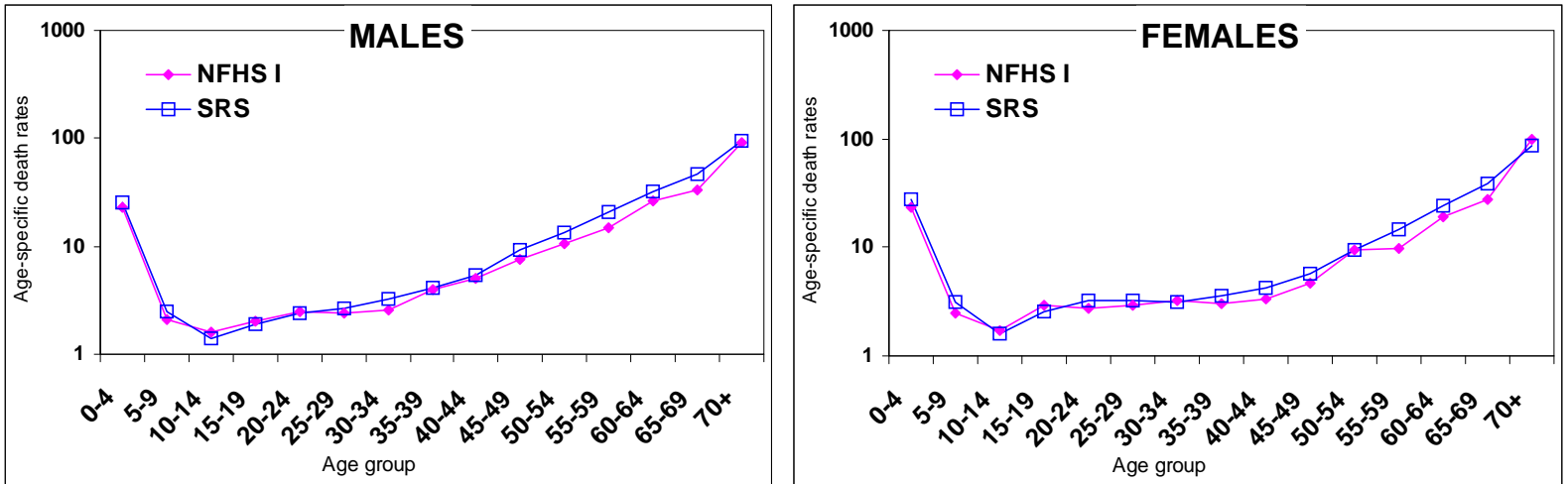

Sources: IIPS \& ORC Macro, 1995.

Appendix 2. Comparison of age specific death rates between NFHS II (1997-1998) and SRS (1997) for India
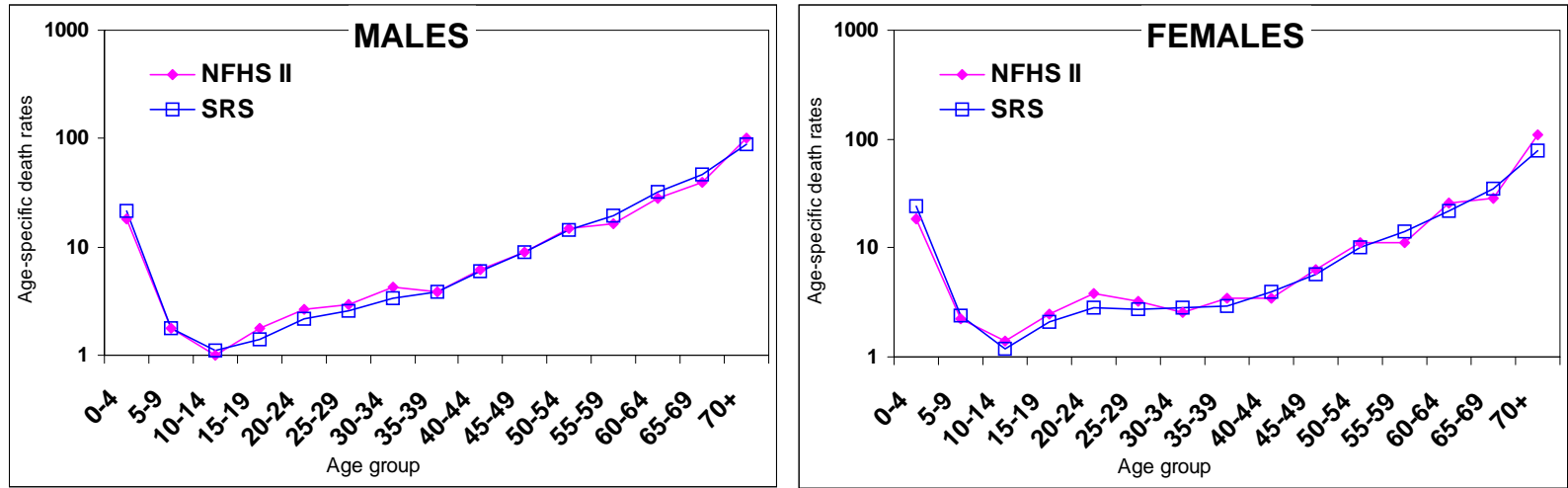

Sources: IIPS \& ORC Macro, 2000. 


\section{Appendix 3. Socio-demographic indicators of India and its states}

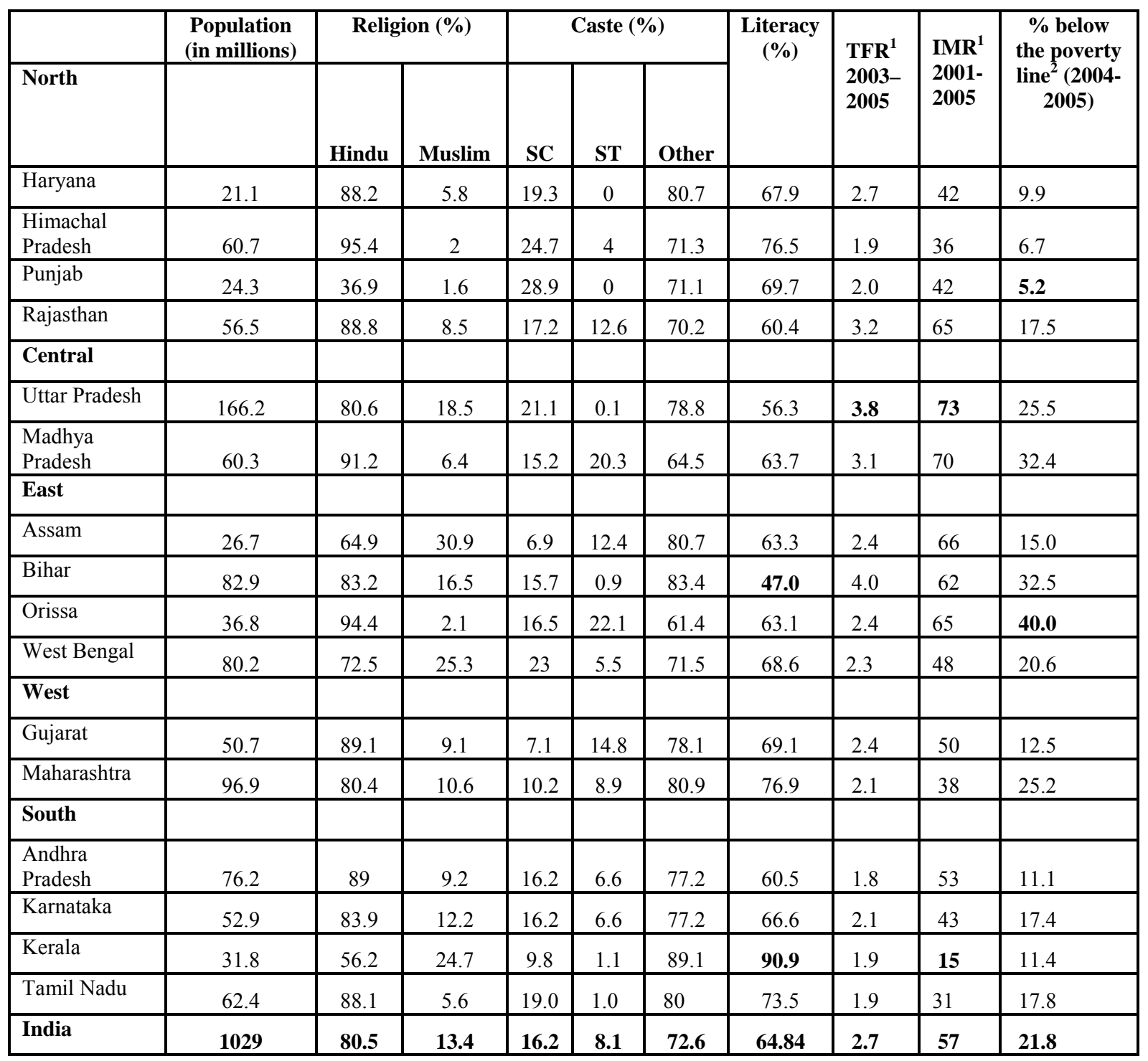

Notes: 1. Data on population size, religion, caste, and literacy come from the 2001 census (office of RGI \& Census Commissioner, 2001)

${ }^{1}$ TFR and IMR is collected from NFHS III, 2005-2006. ${ }^{2}$ The data on poverty comes from Press Information Bureau, Government of India, downloaded from http://www.indiastat.com.

2.As we provide information for 16 major states out of 28 states, the total sum of the population of these 16 states is not equal to that of India. 
Appendix 4. Temporary life expectancy $\left(\mathrm{e}_{0 / 60}\right)$ by sex in India and its states, 1971-2004

\begin{tabular}{|c|c|c|c|c|c|c|c|c|c|c|c|c|c|c|}
\hline \multirow{2}{*}{ Region } & \multicolumn{2}{|c|}{$1971-75$} & \multicolumn{2}{|c|}{ 1976-80 } & \multicolumn{2}{|c|}{ 1981-85 } & \multicolumn{2}{|c|}{$1986-90$} & \multicolumn{2}{|c|}{ 1991-95 } & \multicolumn{2}{|c|}{ 1996-00 } & \multicolumn{2}{|c|}{ 2000-04 } \\
\hline & $\mathbf{M}$ & $\mathbf{F}$ & $\mathbf{M}$ & $\mathbf{F}$ & $\mathbf{M}$ & $\mathbf{F}$ & $\mathbf{M}$ & $\mathbf{F}$ & $\mathbf{M}$ & $\mathbf{F}$ & $\mathbf{M}$ & $\mathbf{F}$ & $\mathbf{M}$ & $\mathbf{F}$ \\
\hline Andhra Pradesh & 42.6 & 42.5 & 44.9 & 45.2 & 48.5 & 49.0 & 49.3 & 49.8 & 50.7 & 51.9 & 51.3 & 52.1 & 51.3 & 51.8 \\
\hline Assam & 46.3 & 40.1 & 48.0 & 43.8 & 48.6 & 44.5 & 49.3 & 45.9 & 50.4 & 46.8 & 50.0 & 48.1 & 50.4 & 48.3 \\
\hline Bihar & NA & NA & NA & NA & 45.6 & 44.6 & 47.1 & 45.2 & 49.4 & 46.5 & 50.0 & 48.2 & 49.8 & 48.2 \\
\hline Gujarat & 42.4 & 41.0 & 43.9 & 43.2 & 46.8 & 47.9 & 48.6 & 48.0 & 50.6 & 50.7 & 51.7 & 51.6 & 51.6 & 51.5 \\
\hline Haryana & 48.4 & 45.4 & 47.3 & 43.5 & 49.8 & 47.6 & 50.9 & 49.1 & 50.9 & 50.4 & 51.3 & 50.6 & 51.9 & 50.7 \\
\hline Himachal & 45.4 & 43.7 & 48.3 & 45.9 & 49.1 & 50.2 & 50.9 & 50.5 & 51.3 & 52.7 & 52.7 & 52.9 & 52.7 & 53.0 \\
\hline Karnataka & 46.7 & 45.6 & 47.4 & 46.5 & 49.7 & 49.6 & 50.0 & 50.4 & 50.7 & 51.4 & 51.9 & 52.6 & 52.0 & 52.4 \\
\hline Kerala & 50.7 & 51.2 & 52.6 & 53.5 & 53.6 & 55.3 & 55.0 & 56.4 & 56.0 & 57.5 & 56.2 & 57.8 & 55.8 & 57.8 \\
\hline Maharashtra & 45.6 & 45.6 & 47.4 & 46.5 & 49.8 & 49.6 & 51.4 & 50.4 & 52.3 & 51.4 & 53.0 & 52.6 & 53.0 & 53.7 \\
\hline Madhya Pradesh & 41.2 & 39.0 & 42.2 & 40.7 & 44.0 & 43.0 & 45.3 & 43.8 & 46.1 & 45.2 & 47.6 & 46.8 & 47.9 & 46.8 \\
\hline Orissa & 40.8 & 40.1 & 43.3 & 41.7 & 45.2 & 44.6 & 45.6 & 45.2 & 47.1 & 46.5 & 48.3 & 48.2 & 48.8 & 48.2 \\
\hline Punjab & 48.0 & 46.1 & 49.0 & 47.0 & 50.7 & 49.9 & 51.4 & 51.2 & 51.8 & 52.4 & 52.8 & 53.0 & 52.8 & 53.1 \\
\hline Rajasthan & 42.2 & 39.6 & 43.5 & 42.8 & 45.5 & 43.8 & 47.0 & 45.5 & 48.9 & 48.3 & 50.0 & 48.9 & 49.8 & 49.1 \\
\hline Tamil Nadu & 43.1 & 43.0 & 45.4 & 45.2 & 47.9 & 46.8 & 50.3 & 50.1 & 52.1 & 52.7 & 52.9 & 53.6 & 52.8 & 53.7 \\
\hline Uttar Pradesh & 39.3 & 34.4 & 41.3 & 36.4 & 43.6 & 40.4 & 46.1 & 43.3 & 48.1 & 46.2 & 49.3 & 47.3 & 49.6 & 48.0 \\
\hline West Bengal & NA & NA & NA & NA & 47.0 & 47.7 & 50.2 & 50.0 & 51.3 & 51.1 & 52.0 & 52.1 & 51.8 & 51.9 \\
\hline India Rural & 44.5 & 40.2 & 43.7 & 41.9 & 45.7 & 44.3 & 47.3 & 46.2 & 49.0 & 48.2 & 49.9 & 49.5 & 50.2 & 49.6 \\
\hline India Urban & 49.4 & 48.4 & 49.9 & 49.4 & 51.1 & 51.1 & 51.8 & 52.2 & 52.6 & 53.0 & 53.3 & 53.6 & 53.6 & 53.7 \\
\hline India & 44.0 & 41.0 & 45.0 & 43.0 & 47.0 & 46.0 & 48.0 & 48.0 & 50.0 & 49.0 & 51.0 & 50.0 & 51.0 & 50.0 \\
\hline
\end{tabular}

Note: $\mathrm{M}$ - males, F - females, NA - data are not available.

Appendix 5a. Probabilities of dying between exact ages 0 and 15 (x 1000).

\begin{tabular}{lllllllllllllll}
\hline Region & $\mathbf{1 9 7 0}-\mathbf{7 5}$ & $\mathbf{1 9 7 6 - 8 0}$ & $\mathbf{1 9 8 1 - 8 5}$ & $\mathbf{1 9 8 6}-\mathbf{9 0}$ & $\mathbf{1 9 9 1 - 9 5}$ & $\mathbf{1 9 9 6 - 0 0}$ & $\mathbf{2 0 0 0 - 0 4}$ \\
\hline \multirow{2}{*}{ Andhra Pradesh } & $\mathrm{M}$ & $\mathrm{F}$ & $\mathrm{M}$ & $\mathrm{F}$ & $\mathrm{M}$ & $\mathrm{F}$ & $\mathrm{M}$ & $\mathrm{F}$ & $\mathrm{M}$ & $\mathrm{F}$ & $\mathrm{M}$ & $\mathrm{F}$ & $\mathrm{M}$ & $\mathrm{F}$ \\
Assam & 225 & 226 & 196 & 194 & 138 & 134 & 125 & 124 & 101 & 91 & 88 & 89 & 85 & 102 \\
Bihar & 248 & 248 & 182 & 191 & 189 & 191 & 170 & 176 & 156 & 163 & 129 & 136 & 127 & 139 \\
Gujarat & $\mathrm{NA}$ & $\mathrm{NA}$ & $\mathrm{NA}$ & $\mathrm{NA}$ & 190 & 222 & 167 & 198 & 130 & 154 & 120 & 144 & 132 & 165 \\
Haryana & 241 & 270 & 214 & 234 & 167 & 152 & 141 & 158 & 107 & 116 & 89 & 105 & 94 & 112 \\
Himachal & 156 & 201 & 170 & 229 & 127 & 165 & 109 & 144 & 100 & 126 & 95 & 123 & 83 & 128 \\
Karnataka & 193 & 211 & 148 & 183 & 127 & 122 & 103 & 121 & 92 & 90 & 80 & 82 & 83 & 87 \\
Kerala & 173 & 184 & 160 & 175 & 124 & 130 & 120 & 121 & 106 & 104 & 82 & 85 & 80 & 95 \\
Maharashtra & 109 & 114 & 81 & 81 & 62 & 52 & 41 & 38 & 27 & 22 & 26 & 17 & 34 & 17 \\
Madhya Pradesh & 189 & 196 & 158 & 172 & 121 & 129 & 98 & 105 & 84 & 88 & 66 & 70 & 68 & 69 \\
Orissa & 263 & 294 & 251 & 268 & 222 & 244 & 202 & 224 & 185 & 198 & 154 & 175 & 151 & 177 \\
Punjab & 254 & 262 & 219 & 242 & 194 & 203 & 191 & 193 & 162 & 178 & 138 & 144 & 134 & 152 \\
Rajasthan & 157 & 195 & 143 & 186 & 107 & 133 & 90 & 113 & 77 & 96 & 66 & 84 & 69 & 85 \\
Tamil Nadu & 139 & 168 & 124 & 143 & 121 & 141 & 111 & 138 & 100 & 111 & 73 & 85 & 93 & 98 \\
Uttar Pradesh & 223 & 220 & 189 & 194 & 144 & 156 & 106 & 119 & 78 & 79 & 62 & 66 & 70 & 67 \\
West Bengal & 300 & 379 & 267 & 347 & 224 & 276 & 184 & 231 & 149 & 182 & 129 & 165 & 124 & 152 \\
\hline India & NA & NA & NA & NA & 176 & 154 & 120 & 122 & 103 & 109 & 92 & 95 & 101 & 107 \\
\hline & $\mathbf{2 2 2}$ & $\mathbf{2 5 3}$ & $\mathbf{2 1 0}$ & $\mathbf{2 3 1}$ & $\mathbf{1 7 3}$ & $\mathbf{1 9 4}$ & $\mathbf{1 4 4}$ & $\mathbf{1 6 3}$ & $\mathbf{1 2 4}$ & $\mathbf{1 3 7}$ & $\mathbf{1 0 8}$ & $\mathbf{1 2 4}$ & $\mathbf{1 0 4}$ & $\mathbf{1 2 5}$ \\
\hline
\end{tabular}


Appendix 5b. Probabilities of dying between exact ages 15 and 60 (x 1000).

\begin{tabular}{|c|c|c|c|c|c|c|c|c|c|c|c|c|c|c|}
\hline Name & 197 & 75 & & & 198 & 85 & 1 & & 19 & 5 & & 00 & & 4 \\
\hline & $\mathbf{M}$ & $\mathbf{F}$ & $\mathbf{M}$ & $\mathbf{F}$ & $\mathbf{M}$ & $\mathbf{F}$ & $\mathbf{M}$ & $\mathbf{F}$ & $\mathbf{M}$ & $\mathbf{F}$ & $\mathbf{M}$ & $\mathbf{F}$ & $\mathbf{M}$ & $\mathbf{F}$ \\
\hline Andhra Pradesh & 399 & 344 & 331 & 275 & 291 & 235 & 285 & 214 & 267 & 208 & 284 & 204 & 285 & 170 \\
\hline Assam & 437 & 448 & 395 & 399 & 367 & 349 & 332 & 309 & 307 & 287 & 316 & 294 & 310 & 266 \\
\hline Bihar & NA & NA & NA & NA & 298 & 311 & 277 & 276 & 262 & 263 & 248 & 249 & 213 & 190 \\
\hline Gujarat & 355 & 277 & 342 & 254 & 314 & 246 & 286 & 217 & 266 & 187 & 249 & 170 & 232 & 147 \\
\hline Haryana & 202 & 215 & 238 & 247 & 221 & 205 & 209 & 190 & 240 & 165 & 241 & 157 & 249 & 140 \\
\hline Himachal & 284 & 313 & 276 & 282 & 294 & 210 & 237 & 199 & 248 & 184 & 211 & 165 & 198 & 155 \\
\hline Karnataka & 315 & 300 & 302 & 266 & 272 & 207 & 263 & 188 & 265 & 184 & 274 & 182 & 259 & 153 \\
\hline Kerala & 253 & 175 & 221 & 147 & 238 & 122 & 217 & 107 & 209 & 99 & 199 & 95 & 183 & 96 \\
\hline Maharashtra & 315 & 250 & 303 & 241 & 263 & 200 & 249 & 180 & 240 & 184 & 244 & 164 & 227 & 165 \\
\hline Madhya Pradesh & 350 & 321 & 316 & 289 & 292 & 246 & 263 & 241 & 279 & 236 & 291 & 244 & 272 & 209 \\
\hline Orissa & 409 & 393 & 378 & 354 & 308 & 286 & 289 & 274 & 296 & 232 & 289 & 251 & 277 & 218 \\
\hline Punjab & 222 & 181 & 195 & 155 & 215 & 180 & 231 & 168 & 251 & 154 & 244 & 170 & 222 & 148 \\
\hline Rajasthan & 344 & 291 & 318 & 261 & 304 & 243 & 278 & 197 & 261 & 181 & 246 & 156 & 217 & 144 \\
\hline Tamil Nadu & 355 & 360 & 314 & 306 & 303 & 264 & 280 & 219 & 266 & 196 & 263 & 187 & 236 & 178 \\
\hline Uttar Pradesh & 350 & 340 & 337 & 303 & 312 & 285 & 292 & 253 & 272 & 237 & 257 & 224 & 253 & 221 \\
\hline West Bengal & NA & NA & NA & NA & 281 & 254 & 255 & 225 & 238 & 201 & 232 & 194 & 206 & 154 \\
\hline India & 338 & 311 & 321 & 276 & 288 & 246 & 272 & 224 & 260 & 209 & 258 & 198 & 243 & 179 \\
\hline
\end{tabular}

